\title{
PENINGKATAN KETERAMPILAN BERPIKIR KRITIS, KOMUNIKASI, KOLABORASI DAN KREATIVITAS MELALUI MODEL PEMBELAJARAN PROJECT BASED LEARNING DI SMA NEGERI 1 SETELUK
}

\author{
YUNITA RISKAYANTI \\ SMA Negeri 1 Seteluk Kabupaten Sumbawa Barat \\ e-mail : yunita.riskayanti@gmail.com
}

\begin{abstract}
Based on observations during the learning process at SMA Negeri 1 Seteluk, many teachers still use the lecture method so that they cannot develop 4C skills in students, the learning process does not involve students. One of the ways that educators practice $4 \mathrm{C}$ skills is by implementing a project based learning model. The purpose of this study was to improve 4C skills, namely critical thinking skills, communication, collaboration and creativity in students through a project-based learning model on alkane-derived carbon compounds. This research method using descriptive method. The target of this research is 66 students of class XII Mia 1 and XII Mia 2 SMA Negeri 1 Seteluk. The research instrument was attitude observation, skill assessment and product assessment. and data analysis using descriptive analysis. The results of this study indicate that students are more active during the learning process and can improve 4C skills, namely critical thinking skills, communication, collaboration and creativity in students.
\end{abstract}

Keywords: critical thinking, collaboration, creativity, project based learning

\begin{abstract}
ABSTRAK
Berdasarkan pengamatan selama proses pembelajaran di SMA Negeri 1 Seteluk guru masih banyak yang menggunakan metode ceramah sehingga tidak bisa mengembangkan keterampilan $4 \mathrm{C}$ pada peserta didik, proses belajarnya kurang melibatkan peserta didik. Salah satu cara yang dilakukan pendidik untuk melatih keterampilan $4 \mathrm{C}$ yaitu menerapkan model pembelajaran project based learning. Tujuan penelitian ini adalah untuk meningkatkan keterampilan 4C yaitu keterampilan berfikir kritis, komunikasi, kolaborasi dan kreativitas pada peserta didik melalui model pembelajaran project based learning pada materi senyawa karbon turunan alkana. Metode penelitian ini menggunakan metode deskriptif. Sasaran pelaksanaan penelitian ini adalah siswa kelas XII Mia 1 dan XII Mia 2 SMA Negeri 1 Seteluk sebanyak 66 anak. Instrument penelitian ini adalah observasi sikap, penilaian keterampilan dan penilaian produk. dan analisis datanya menggunakan analisis deskriptif. Hasil penelitian ini menunjukkan bahwa peserta didik lebih aktif saat proses belajar dan dapat meningkatkan keterampilan $4 \mathrm{C}$ yaitu keterampilan berfikir kritis, komunikasi, kolaborasi dan kreativitas pada peserta didik
\end{abstract}

Kata Kunci: berfikir kritis, kolaborasi, kreativitas, project based learning,

\section{PENDAHULUAN}

Dampak globalisasi menyentuh berbagai bidang kehidupan termasuk pendidikan. Dunia pendidikan di tuntut agar bisa mengembangkan keterampilan abad 21. Untuk membuat guru dan sekolah berubah, perlu ada upaya untuk menyadarkan bahwa perubahan dunia di abad 21 akan lebih dahsyat dibandingkan abad sebelumnya, sehingga tugas pendidik tidak hanya sekedar memberi bekal ilmu namun harus menempa peserta didik untuk bisa bertahan di zaman yang akan datang (Andri, T. 2018:18). Peserta didik dituntut memiliki keterampilan 
abad 21 agar mereka menjadi pribadi yang memiliki keterampilan untuk hidup di abad 21 dengan berbagai peluang dan tantangan yang akan dihadapi di era kemajuan teknologi dan informasi. Dalam mengajarkan keterampilan abad 21 ini, guru dapat mengintegrasikan menjadi kegiatan tersendiri berbentuk aktivitas pembelajaran, Siswa yang mempraktikkan sendiri dan guru berperan sebagai fasilitator (Widodo, S. \& Wardani, R. K., 2020). Beberapa keterampilan untuk menghadapi tantangan perkembangan abad 21 adalah keterampilan 4C yaitu keterampilan berfikir kritis, komunikasi, kolaborasi dan kreativitas, mengintegrasikan keterampilan abad 21 dalam proses pembelajaran secara efektif menjadi sangat penting (Sari, A.K,. \& Trisnawati, W. 2019)

Perlunya pendekatan pembelajaran yang berpusat pada peserta didik yang bisa memberikan bekal kompetensi, pengetahuan dan kecakapan yang mereka butuhkan (Amir, T. 2016:3-4). Berdasarkan pengamatan pendidik selama proses pembelajaran di SMA Negeri 1 Seteluk, pendidik masih banyak yang menggunakan metode ceramah sehingga belum bisa mengembangkan keterampilan 4C pada peserta didik, proses belajarnya kurang melibatkan peserta didik, sehingga reformasi pembelajaran yang menggeser dari pembelajaran yang berpusat pada pendidik ke pembelajaran yang berpusat pada peserta didik, kerjasama tim serta pembelajaran yang berkaitan dengan konteks kehidupan sehari-hari merupakan jawaban dari upaya untuk mengembangkan keterampilan $4 \mathrm{C}$ pada peserta didik.

Salah satu cara yang dilakukan pendidik untuk melatih keterampilan 4C yaitu menerapkan model pembelajaran project based learning atau dalam bahasa Indonesia dikenal dengan istilah pembelajaran berbasis proyek. Model pembelajaran ini dapat mendorong peserta didik berfikir kritis, kreatif, terampil dalam menyelesaikan masalah. Project Based Learning merupakan model pembelajaran yang menggunakan proyek atau kegiatan sebagai inti pembelajaran (Kemendikbud, 2015:4). Project based learning dapat meningkatkan motivasi belajar, kreativitas dan kemampuan berfikir kritis peserta didik (Insyasiska, D. et al. 2015).

Menggunakan model project based learning menjadi salah satu solusi untuk meningkatkan penguasaan keterampilan $4 \mathrm{C}$ siswa karena pendidik menemukan bahwa peserta didik lebih aktif dalam berkolaborasi sesama tim, lebih kreatif dan kritis serta menuntut kerja sama peserta didik dalam menyelesaikan tugas/proyek. Best practice ini diharapkan bermanfaat:

1. Bagi siswa : Memperoleh pengalaman belajar yang lebih menarik dan menyenangkan dan dapat meningkatkan keterampilan 4C yaitu berfikir kritis, komunikasi, kolaborasi dan kreativitas

2. Bagi guru : Mampu menciptakan pembelajaran yang aktif, inovatif, kreatif dan menyenangkan dan dapat meningkatkan peran guru sebagai fasilitator

3. Bagi sekolah : Menerapkan metode yang dilaksanakan terhadap pelajaran kimia atau pelajaran yang lain

\section{METODE PENELITIAN}

Best Practice ini dilaksanakan pada 6 Januari sampai 4 Februari 2021 bertempat di kelas XII Mia 1 dan XII Mia 2 SMA Negeri 1 Seteluk. Bahan yang digunakan adalah materi kelas XII Mia Semester genap Tahun Pelajaran 2020/2021 pada Materi Pokok Senyawa Karbon Turunan Alkana, dengan rincian KD sebagai berikut :

3.9 Menganalisis struktur, tatanama, sifat, sintesis, dan kegunaan senyawa karbon

4.9 Menyajikan rancangan percobaan sintesis senyawa karbon, identifikasi gugus fungsi dan/atau penafsiran data spektrum inframerah (IR)

Metode penelitian ini menggunakan metode deskriptif sebab menggambarkan bagaimana proses pembelajaran dan hasil yang dicapai saat menerapkan model pembelajaran project based learning dalam pembuatan komik pendidikan. Alat-alat yang digunakan dalam 
pembuatan komik pendidikan ini adalah, laptop, Hp android, LKPD, contoh komik pendidikan. Instrument yang digunakan untuk mengamati proses pembelajaran adalah lembar observasi sikap, penilaian keterampilan dan penilaian produk. Prosedur penelitiannya pendidik menyiapkan contoh-contoh komik pendidikan dan mempersiapkan LKPD. Adapun langkah-langkah kegiatan adalah:

\section{Pertemuan ke - 1}

a. Peserta didik dibagi ke dalam beberapa kelompok, terdiri antara 4 atau 5 orang masingmasing kelompok

b. Memberikan contoh-contoh komik pendidikan pada masing-masing kelompok

c. Menjelaskan cara membuat storyline komik pendidikan

d. Membagi sub materi kepada masing-masing kelompok untuk dibuat menjadi komik pendidikan

e. Membaca materi sesuai sub materi yang sudah diberikan

f. Diskusi membuat storyline

\section{Pertemuan ke - 2}

a. Komunikasikan hasil pembuatan storyline, guru membantu menyempurnakan hasil storyline-nya

b. Pengambilan gambar tokoh komik

Tokoh komik berasal dari anggota yang terdiri dari 2 atau 3 orang. Pengambilan gambar bisa dilakukan di sekolah, di rumah atau di tempat lain, sesuai dengan cerita dalam storyline apabila pengambilan gambar di luar sekolah, maka pada pertemuan ke-2 gambar komik sudah tersedia

c. Download dan install aplikasi komik life 3 menggunakan laptop

d. Menjelaskan cara edit komik menggunaakan aplikasi komik life 3

\section{Pertemuan ke-3}

a. Edit komik menggunakan aplikasi komik life 3

b. Guru tetap membimbing masing-masing kelompok agar menghasilkan komik yang sempurna

\section{Pertemuan ke 4}

a. Pengumpulan produk

\section{HASIL DAN PEMBAHASAN}

Hasil kegiatan ini pendidik mampu meningkatkan kualitas pembelajaran, berdasarkan survey sikap untuk melihat keaktifan peserta didik selama proses pembelajaran, keterampilan komunikasi dan penilaian produk komik kimia, penilaian produk ini bisa menjadi landasan hasil kreatifitas dan berfikir kritis dari peserta didik, hasil penilaian pendidik disajikan dalam diagram berikut ini.

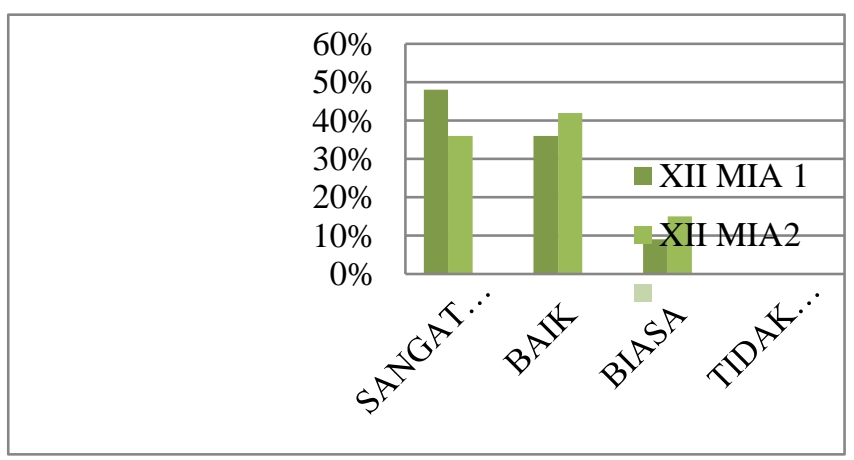


Gambar 1. Grafik persentase pencapaian keterampilan berfikir kritis

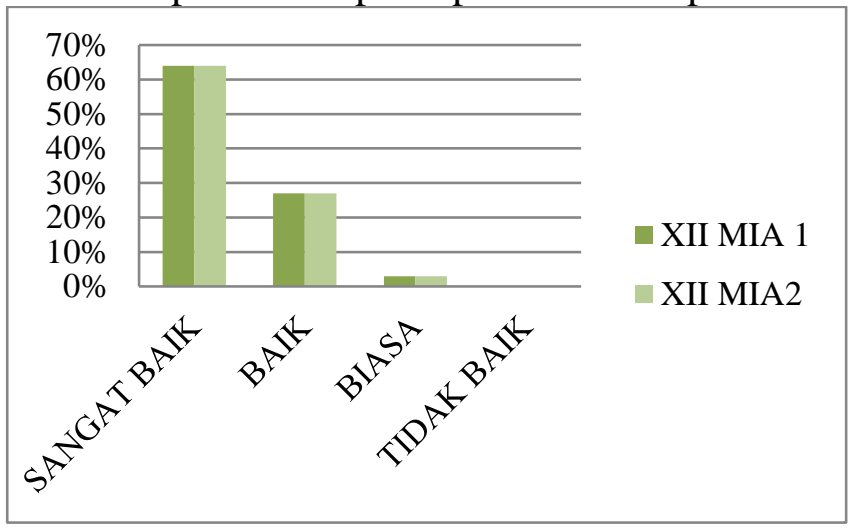

Gambar 2. Grafik persentase pencapaian keterampilan komunikasi

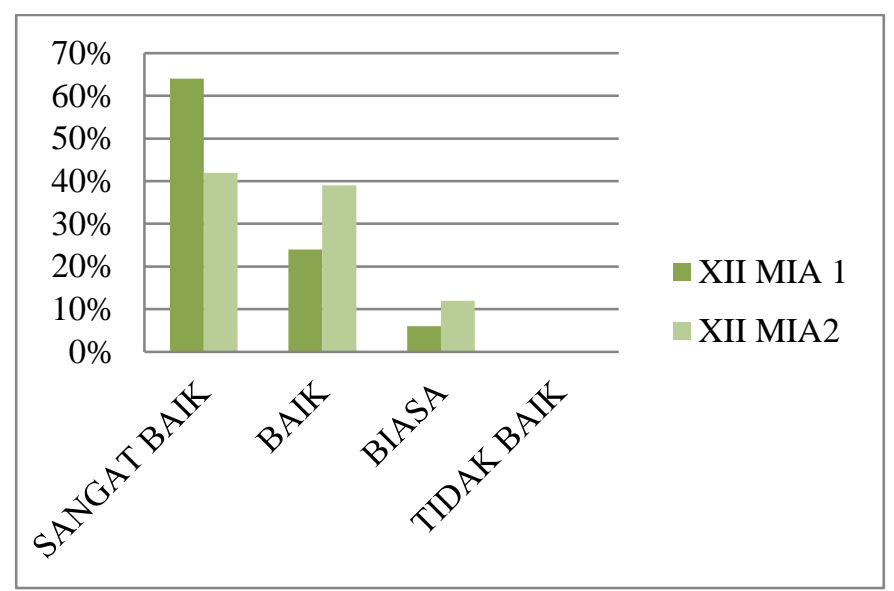

Gambar 3. Grafik persentase pencapaian kreativitas

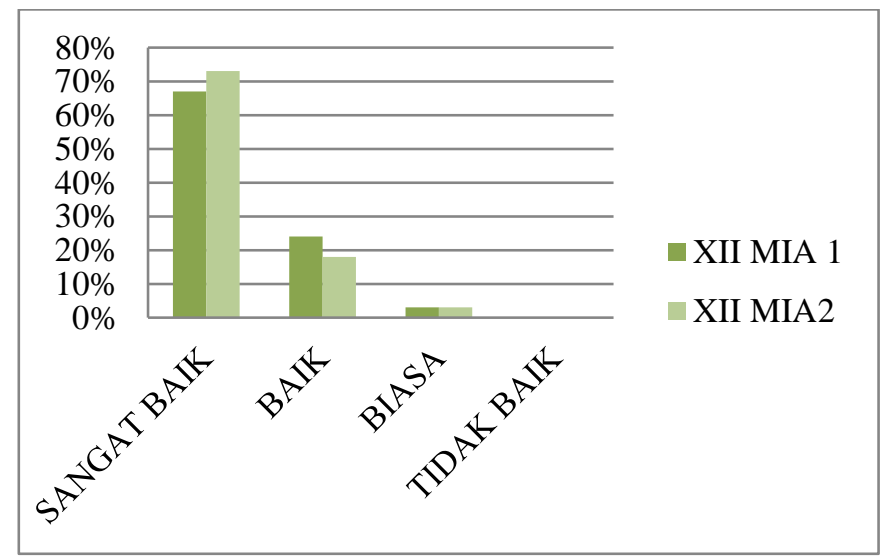

Gambar 4. Grafik persentase pencapaian kolaborasi

Berdasarkan grafik persentase pencapaian keterampilan berfikir kritis,kreatif, kolaborasi dan komunikasi, Hasil yang dapat dilaporkan dari best practice ini diuraikan sebagai berikut.

1. Proses pembelajaran dengan menerapkan model pembelajaran project based learning pada pembuatan komik pendidikan bisa membuat siswa lebih aktif dalam diskusi kelompok maupun aktif dalam bertanya kepada guru apabila ada hal yang masih belum dipahami 
2. Penerapan model pembelajaran project based learning dapat meningkatkan keterampilan berfikir kritis dan kreatif pada peserta didik. Ini dibuktikan dari hasil komik pendidikan karya peserta didik, dari awal menentukan cerita komik, membuat dialog komik, pengambilan gambar sampai editing komik proses ini membutuhkan konsep ide yang matang dan kreativitas dari peserta didik, dan ini sudah dibuktikan dengan hasil yang memuaskan

3. Penerapan model pembelajaran project based learning dapat meningkatkan keterampilan komunikasi pada peserta didik. Terbukti dalam pembuatan komik mereka saling bertukar pikiran dalam menentukan cerita maupun dialog komik, sikap saling menghargai perbedaan pendapat, serta dapat menyampaikan hasil pembuatan storyline ke depan kelas untuk didiskusikan bersama teman lainnya maupun dengan guru

Setelah menerapkan model pembelajaran project based learning pada materi senyawa karbon turunan alkana dengan cara membuat komik pendidikan maka pendidik menemukan banyak sekali perubahan aktivitas dari peserta didik, semakin aktif dan dapat berkarya sesuai imajinasi mereka, peserta didik bersemangat dalam hal berdiskusi antar kelompok bukan saja terjadi di sekolah tetapi kadang berlanjut sampai rumah. Saat edit gambar komik mereka berusaha mendesain agar tampilannya bagus dan menggunakan dialog yang mudah dipahami, menceritakan kisah mereka dalam kehidupan sehari-hari, jadi menurut pengamatan peneliti selama proses kegiatan belajar saat penerapan project based learning, bisa meningkatkan keterampilan berfikir kritis, komunikasi, kolaborasi dan kreativitas pada peserta didik.

Pada pertemuan pertama peserta didik diberikan gambaran contoh komik dan menjelaskan cara pembuatan komik yang diawali dengan pembuatan storyline, peserta didik sangat aktif dan bersemangat bertanya, baik dengan teman kelompok maupun dengan pendidik, menurut mereka ini adalah hal baru dalam proses pembelajaaran, masih banyak yang bingung dalam proses pembuatan storyline, mereka belum pernah membuat komik, kegiatan ini membutuhkan keterampilan berfikir kritis untuk menghasilkan cerita komik yang baik. pendidik berusaha memberikan masukan agar gambaran cerita dan dialog komiknya bisa maksimal hasilnya
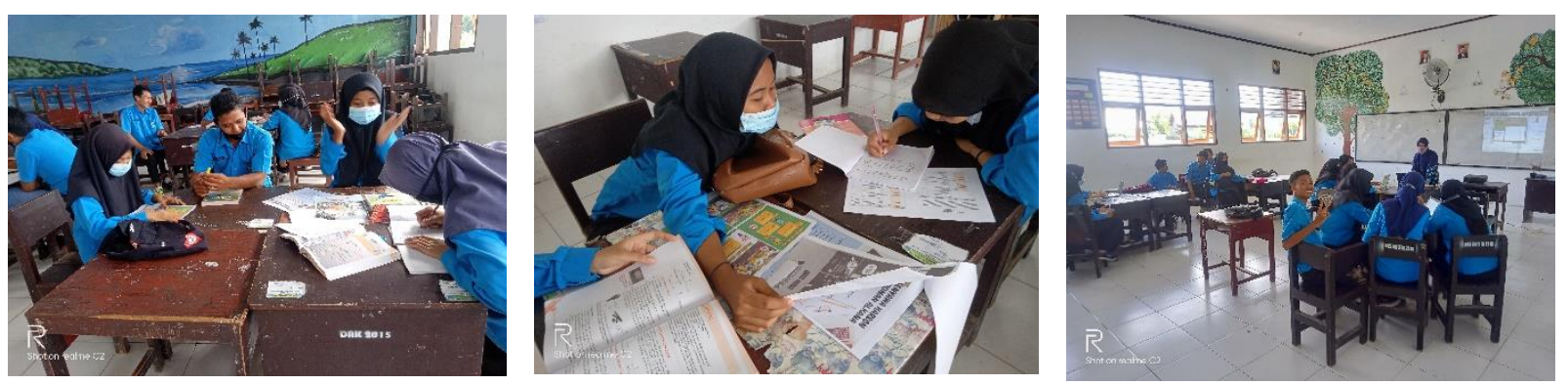

Gambar 5. Penjelasan materi dari guru dan diskusi membuat storyline

Pada pertemuan kedua masing-masing kelompok mempresentasi hasil storyline dan berdiskusi dengan teman-teman lainnya. Akfitas ini dapat meningkatkan keterampilan komunikasi dari peserta didik dan meningkatkan kepercayaan diri mereka. Selain itu peserta didik mengambil gambar komiknya, dengan tokoh komiknya berasal dari kelompok masingmasing, kegiatan ini dapat meningkatkan kreatifitas, saling menghargai dan kekompakan antar kelompok 
Gambaran keaktifan peserta didik pada pertemuan kedua
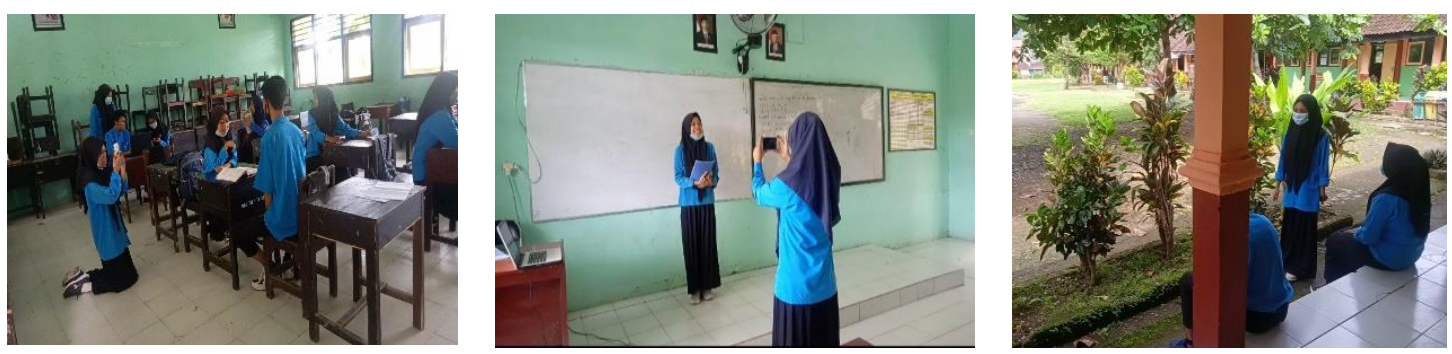

Gambar 6. Pengambilan gambar tokoh komik

Pertemuan ketiga dan keempat masing-masing kelompok masukkan asset komik berupa gambar dan dialog yang sudah disediakan, kegiatan ini membutuhkan kreatifitas dan ketekunan untuk membuat komik sampai selesai. Setelah komik selesai diperiksa oleh pendidik, komik dicetak dan disimpan dalam perpustakaan sekolah, agar bermanfaat bagi guru lain dan bagi peserta didik lainnya.

Gambaran keaktifan peserta didik pada pertemuan ketiga


Gambar 7. Proses pembuatan komik pendidikan

Penggunaan model pembelajaran Project Based Learning berpengaruh terhadap keterampilan kolaborasi (Saenab, S., Yunus, S. R., \& Husain, 2019), selain itu melalui model pembelajaran project based learning dapat meningkatkan motivasi belajar dalam melaksanakan proyek yang dilakukan sehingga dapat meningkatkan sikap aktif pada peserta didik (Handayani, L., 2020). Model pembelajaran project based learning proses pembelajarannya dengan cara memberikan tugas proyek secara berkelompok, seluruh siswa bergerak, berpikir, berdiskusi dan berkolaborasi untuk menyelesaikan proyek dengan baik dan tepat waktu sehingga berpengaruh positif terhadap peningkatan keterampilan berfikir kritis, komunikasi, kolaborasi dan kreativitas dari peserta didik (Maulidah, E., 2019). Project based learning merupakan model pembelajaran dengan pendekatan konstruktivisme yang mampu mengakomodasi keterampilan abad 21, pembelajaran yang berpusat kepada peserta didik, kerjasama tim, serta pembelajaran yang berkaitan dengan konteks kehidupan sehari-hari peserta didik (Mayasari, T et al., 2016)

Selama proses pembuatan komik pendidikan ini ada beberapa masalah yang dihadapi yaitu tidak semua peserta didik memiliki laptop dan masih kesulitan dalam menentukan cerita maupun dialog dalam cerita komik pendidikan, untuk mengatasi masalah tersebut bagi peserta didik yang tidak punya laptop, akan meminjam laptop dari siswa lain atau menggunakan computer yang ada di lab computer, ada juga yang menggunakan smartphone untuk edit komiknya. Kemudian untuk masalah menentukan cerita atau dialog maka akan dibantu guru dengan memberi masukan pada kelompok tersebut untuk dikembangkan lebih lanjut Hasil komik pendidikan yang sudah dikumpulkan oleh peserta didik 

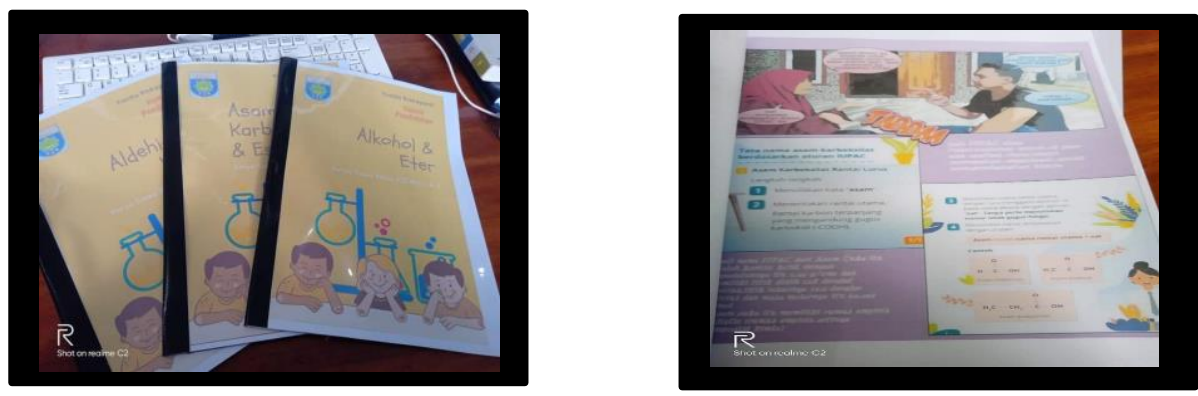

Gambar 8. Hasil pembuatan komik pendidikan

\section{KESIMPULAN}

Berdasarkan uraian di atas dapat ditarik kesimpulan sebagai berikut :

1. Pembelajaran dengan model project based learning layak dijadikan sebagai pembelajaran yang dapat meningkatkan keaktifan peserta didik

2. Pembelajaran dengan model project based learning dapat meningkatkan keterampilan 4C peserta didik yaitu keterampilan berfikir kritis, komunikasi, kolaborasi dan kreativitas

\section{DAFTAR PUSTAKA}

Amir, T. (2016). Inivasi pendidikan melalui problem based learning. Kencana. Jakarta https://books.google.co.id/books?id=qviDwAAQBAJ\&lpg=PP1\&dq=pendidikan\%20a bad\%2021\%20di\%20sekolah\&hl=id\&pg=PR4\#v=onepage\&q\&f=false

Andri, T. (2018). Evolusi guru dan sekolah abad 21. CV jejak. Jawa Barat https://books.google.co.id/books?id=KC9uDwAAQBAJ\&lpg=PP1\&dq=pendidikan\% 20abad\%2021\%20di\%20sekolah\&hl=id\&pg=PA2\#v=onepage \&q=pendidikan\%20aba d\%2021\%20di\%20sekolah\&f=false

Handayani, L. (2020). Peningkatan Motivasi Belajar IPA Melalui Model Pembelajaran Project Based Learning pada Masa Pandemi Covid-19 bagi Siswa SMP Negeri 4 Gunungsari. Jurnal Paedagogy: Jurnal Penelitian dan Pengembangan Pendidikan. Vol. 7 No. 3. p-ISSN: 2355-7761. e-ISSN: 2722-4627. pp. 168-174. http://ojs.ikipmataram.ac.id/index.php/pedagogy/index

Insyasiska, D. (2015). Pengaruh Project Based Learning Terhadap Motivasi Belajar, Kreativitas,Kemampuan Berpikir Kritis,dan Kemampuan Kognitif Siswa Pada Pembelajaran Biologi. Jurnal Pendidikan Biologi Volume 7, Nomor 1, Agustus 2015,9-21. ISSN 2540-9271. http://journal2.um.ac.id/index.php/jpb

Kemendikbud. (2015). Model Pembelajaran Berbasis Proyek Di SMA. Direktorat Pembinaan Sekolah Menengah Atas. Jakarta

Maulidah, E. (2019). Efektifitas Model Project Based Learning (PJBL) Untuk Meningkatkan Keterampilan $4 C$ (critical thinking, creativity, communication, and collaboration) Siswa Kelas IV SDN karang Melok 1 Tamanan Bondowoso. Tesis. Pascasarjana Universitas Islam Negeri Maulana Malik Ibrahim. Malang

Mayasari, T. 2016). Apakah model pembelajaran problem based learning dan project based learning mampu melatihkan keterampilan abad 21?. JPFK, Vol. 2 No. 1, Maret 2016, hal 48 - 55 http://e-journal.ikippgrimadiun.ac.id/index.php/JPFK

Saenab, S., Yunus, S. R., \& Husain. (2019). Pengaruh Penggunaan Model Project Based Learning Terhadap Keterampilan Kolaborasi Mahasiswa Pendidikan IPA. Jurnal Biology Science \& Education. vol 8 no 1 issn 2252-858x/e-ISSN 2541-1225. 39

Sari, A.K \& Trisnawati, W. (2019). Integrasi keterampilan abad 21 dAlam modul Sociolinguistics: keterampilan 4c (Collaboration, Communication, Critical Thinking, dan Creativity). Jurnal Muara Pendidikan Vol. 4 No. 2 (2019). E-ISSN 2621-0703PISSN 2528-6250 
Widodo, S \& Wardani, R., K. (2020). Keterampilan Abad 21 4C (Communication, Collaborattion, Critical Thinking and Problem Solving, Creativity and Innovation) Di Sekolah Dasar. Jurnal program Studi PGMI. Volume 7, Nomor 2, p-ISSN: 24423661; e-ISSN: 2477-667X, 196 